\title{
Diagnosis and treatment of hyponatremia: a systematic review of clinical practice guidelines and consensus statements
}

Evi V Nagler ${ }^{1,2,3^{*}}$, Jill Vanmassenhove ${ }^{2}$, Sabine N van der Veer ${ }^{1,4}$, Ionut Nistor ${ }^{1,5}$, Wim Van Biesen ${ }^{1,2}$, Angela C Webster ${ }^{3,6,7}$ and Raymond Vanholder ${ }^{1,2}$

\begin{abstract}
Background: Hyponatremia is a common electrolyte disorder. Multiple organizations have published guidance documents to assist clinicians in managing hyponatremia. We aimed to explore the scope, content, and consistency of these documents.

Methods: We searched MEDLINE, EMBASE, and websites of guideline organizations and professional societies to September 2014 without language restriction for Clinical Practice Guidelines (defined as any document providing guidance informed by systematic literature review) and Consensus Statements (any other guidance document) developed specifically to guide differential diagnosis or treatment of hyponatremia. Four reviewers appraised guideline quality using the 23-item AGREE II instrument, which rates reporting of the guidance development process across six domains: scope and purpose, stakeholder involvement, rigor of development, clarity of presentation, applicability, and editorial independence. Total scores were calculated as standardized averages by domain.

Results: We found ten guidance documents; five clinical practice guidelines and five consensus statements. Overall, quality was mixed: two clinical practice guidelines attained an average score of $>50 \%$ for all of the domains, three rated the evidence in a systematic way and two graded strength of the recommendations. All five consensus statements received AGREE scores below $60 \%$ for each of the specific domains.

The guidance documents varied widely in scope. All dealt with therapy and seven included recommendations on diagnosis, using serum osmolality to confirm hypotonic hyponatremia, and volume status, urinary sodium concentration, and urinary osmolality for further classification of the hyponatremia. They differed, however, in classification thresholds, what additional tests to consider, and when to initiate diagnostic work-up. Eight guidance documents advocated hypertonic $\mathrm{NaCl}$ in severely symptomatic, acute onset ( $<48 \mathrm{~h}$ ) hyponatremia. In chronic ( $>48 \mathrm{~h}$ ) or asymptomatic cases, recommended treatments were $\mathrm{NaCl} 0.9 \%$, fluid restriction, and cause-specific therapy for hypovolemic, euvolemic, and hypervolemic hyponatremia, respectively. Eight guidance documents recommended limits for speed of increase of sodium concentration, but these varied between 8 and $12 \mathrm{mmol} / \mathrm{L}$ per $24 \mathrm{~h}$. Inconsistencies also existed in the recommended dose of $\mathrm{NaCl}$, its initial infusion speed, and which second line interventions to consider.
\end{abstract}

Conclusions: Current guidance documents on the assessment and treatment of hyponatremia vary in methodological rigor and recommendations are not always consistent.

Keywords: Clinical practice guideline, Hyponatremia, Systematic review

\footnotetext{
*Correspondence: evi.nagler@ugent.be

${ }^{1}$ European Renal Best Practice (ERBP), guidance body of the European Renal

Association European Dialysis and Transplant Association (ERA-EDTA), De

Pintelaan 185, Ghent 9000, Belgium

${ }^{2}$ Renal Division, Department of Internal Medicine, Ghent University Hospital,

De Pintelaan 185, Ghent 9000, Belgium

Full list of author information is available at the end of the article
}

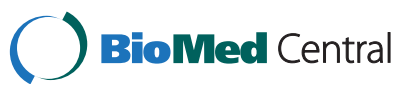

2014 Nagler et al.; licensee BioMed Central Ltd. This is an Open Access article distributed under the terms of the Creative Commons Attribution License (http://creativecommons.org/licenses/by/4.0), which permits unrestricted use, distribution, and reproduction in any medium, provided the original work is properly credited. The Creative Commons Public Domain Dedication waiver (http://creativecommons.org/publicdomain/zero/1.0/) applies to the data made available in this article, unless otherwise stated. 


\section{Background}

Hyponatremia is the most common electrolyte disorder in clinical medicine; it represents an excess of water relative to total body solute [1]. Hyponatremia usually results from the intake and subsequent retention of electrolyte-free water in response to true hypovolemia due to gastrointestinal solute loss or malnutrition; decreased effective circulating volume due to heart failure or liver cirrhosis; or non-osmotic vasopressin activity due to malignancies, infections, medications, pain, or stress [2]. When defined as a serum sodium concentration below $135 \mathrm{mmol} / \mathrm{L}$, hyponatremia occurs in up to $8 \%$ of the general population and in up to $60 \%$ of hospitalized patients [2,3]. Acute profound hyponatremia can cause brain edema, but also chronic mild hyponatremia is associated with poor health outcomes. Even when comorbid conditions are taken into account, people with a mildly decreased serum sodium concentration have a $30 \%$ higher risk of death and are hospitalized $14 \%$ longer relative to those without hyponatremia $[2,4]$.

Despite the frequency and severity of some of the associated complications, research suggests hyponatremia is often neglected by clinicians [5]. If acquired in hospital, it may take days before the electrolyte disorder is investigated, potentially allowing a further decrease in serum sodium concentration and exposing patients to the dangers of profound hyponatremia. When efforts are made to explore the underlying cause, clinicians use widely different strategies for differential diagnosis, testing is often inadequate and misclassification of the hyponatremia frequently occurs [6,7].

Hyponatremia may be managed clinically by different specialists, such as endocrinologists, nephrologists, geriatricians, or intensivists, and, accordingly, management strategies often vary [5]. Although probably related to variation in awareness, differences in expert opinion on whom and how to treat only add to the confusion over optimal management. For instance, although experts agree that acute symptomatic hyponatremia should be treated with hypertonic saline, the optimal concentrations and methods for determining initial infusion speeds are debated [1]. In addition, the risk of osmotic demyelination syndrome after rapid correction of hyponatremia has fuelled intense debate among experts on whether complications of untreated hyponatremia or complications of treatment pose the greatest risk [8]. As different specialist physicians deal with hyponatremia, consultation of different information and guidance sources may add to the variability in treatment seen in clinical practice today.

Clinical practice guidelines and consensus statements provide recommendations to help evidence-based practice by suggesting the most appropriate diagnostic tests and the most appropriate treatments. Over the years, multiple organizations have developed recommendations to assist clinicians in the management of hyponatremia. To be reliable, these recommendations must be based on a systematic review of the evidence, and have a transparent and multidisciplinary development process [9]. Inconsistencies between recommendations may arise from failing to meet development standards and can only add to unwarranted variability in management. In this study, we aimed to explore the scope, content, and consistency of the existing guidance documents on the diagnosis and management of hyponatremia in adults and children.

\section{Methods}

\section{Criteria for selection of studies}

We included evidence-based clinical practice guidelines and consensus statements on the diagnosis and treatment of hyponatremia. We defined clinical practice guidelines as statements that included recommendations intended to optimize patient care informed by a systematic review of evidence and an assessment of the benefits and harms of alternative care options [9]. We defined consensus statements as documents containing clinically relevant suggestions or recommendations based on the collective opinion of an expert panel [9]. We included all publications independent of language. We excluded guidelines related to the prevention of hyponatremia as well as guidelines relevant to conditions associated with hyponatremia if they were not specifically designed to address hyponatremia. Hence, we excluded guidelines targeting treatment of heart failure, cirrhosis, and cancer unless they were developed with a focus on hyponatremia as a complication. Finally, we also excluded draft unpublished guidelines, conference or discussion papers, personal opinions, and obsolete guidelines replaced by updated recommendations from the same organization.

Search methods for guidelines and consensus statements We searched MEDLINE (1946 to September Week 1, 2014) and EMBASE (1980 to September 2014), combining vocabulary terms and text words for hyponatremia with terms related to clinical practice guidelines and consensus statements. We also searched guideline databases and websites of organizations as well as of selected professional specialist societies in nephrology, endocrinology, and intensive care medicine. A list of the databases and websites along with the full search strategies are outlined in Additional file 1. EN and JV independently screened the titles and abstracts and discarded those that did not meet the inclusion criteria. Full texts for potentially relevant guidelines or consensus statements were retrieved and examined for eligibility. Both the initial screening and subsequent full-paper assessment stage were completed using Early Review Organizing Software [10]. 


\section{Data collection process and data items}

We developed a draft data extraction form which was piloted and modified as necessary. The extracted data included document characteristics (e.g., year of publication, country/region, development team, funding organization), recommendations related to the diagnosis and assessment of hyponatremia, and recommendations related to the treatment of hyponatremia. EN and JV extracted all data using the standardized data extraction form (Additional file 2) and resolved discrepancies by consensus.

\section{Appraisal of guidelines and consensus statements}

Four reviewers independently assessed methodological quality using the Appraisal of Guidelines for Research and Evaluation (AGREE II) instrument [11]. AGREE II is an internationally validated, rigorously developed 23 -item tool used to evaluate six domains of guideline development: scope and purpose, stakeholder involvement, rigor of development, clarity of presentation, applicability, and editorial independence [12] (Additional file 3). The AGREE tool has also been used to assess consensus statements $[13,14]$. The reviewers rated each item on a Likert scale from 1 (Strongly Disagree) to 7 (Strongly Agree). We calculated a total score for each domain by summing up all the scores of the individual items in a domain for each reviewer and then standardizing this total as a percentage of the maximum possible score for that domain, calculated as follows [12]:

$$
\text { Obtained score - Minimum possible score }
$$

Maximum possible score - Minimum possible score

The minimum possible score for each domain equaled the number of questions multiplied by the number of reviewers, multiplied by 1 (strongly disagree). The maximum score for a domain equaled the number of questions multiplied by the number of reviewers, multiplied by 7 (strongly agree). To ensure standardization of each reviewer s approach, all reviewers completed the online training tutorial [15] before starting the project.

In a consensus meeting among the reviewers, we discussed every item for which scores differed by more than 1 point (e.g., 1 versus 3) on the original 7-point scale. Reviewers in turn explained the rationale for their score and had the opportunity to revise their score when they considered this appropriate. We audiotaped the consensus meeting to reliably record the underlying reasons for changing scores.

\section{Synthesis of guideline recommendations}

We conducted a textual descriptive synthesis to analyze the scope, content, and consistency of the included recommendations. EN inductively coded the text manually to identify domains covered by the guidelines. These were crosstabulated with the guidelines and recommendations were inserted into the corresponding cell. For each domain, we compared guideline recommendations to identify similarities and discrepancies. Consistent with the scope of this review, we only tabulated the information on diagnosis and treatment of hyponatremia.

\section{Results}

\section{Search results}

We identified 1,402 citations, of which we excluded 1,367 after screening titles and abstracts because they did not meet our eligibility criteria (Figure 1). We assessed the full text of the remaining 39 citations and excluded 29 because they were not related to the diagnosis or treatment of hyponatremia, were not clinical practice guidelines or consensus statements, or were guidelines replaced by an updated version (Additional file 4). Ultimately, we included five clinical practice guidelines [16-20] and five consensus statements [21-25]. Six of these documents were retrieved through searching the medical databases [18-20,23-25], the other four through the search of guideline databases and professional society websites $[16,17,21,22]$.

Table 1 shows the general characteristics of the included clinical practice guidelines and consensus statements. Eight national or regional organizations from the Netherlands [16], United Kingdom [17], Northern Ireland [22], Spain $[23,25]$, United States [18,19], Australia [21], and two international groups $[20,24]$ published these guidance documents between 2004 and 2014. One document specifically covered children [21], the others primarily targeted adults. Six groups reported undertaking a systematic review and appraisal of the evidence [16-20,24]. Only three were explicit about the level of evidence that underpinned their recommendations $[16,18,20]$, and only two graded the strength of the guidance recommendations themselves $[18,20]$. Five guidance documents covered hyponatremia broadly; one specifically covered it in the setting of primary care, one in liver cirrhosis, one in neurosurgery, and one in exercise-associated hyponatremia. Three included treatment only [23-25], the seven others covered diagnosis as well [16-22]. Two groups reported funding by a governmental institution [16,22], one by the professional societies they represented [20]; the others did not report their funding sources [17-19,21,23-25].

\section{Appraisal of guidelines and consensus statements}

Figure 2 shows the standardized domain scores for each guideline for each of the six quality domains assessed with the AGREE II tool (See Additional file 5 for mean individual scores per item across reviewers). The overall quality of reporting of the guideline development process as assessed by AGREE varied widely both between guidance documents across domains and within guidance 


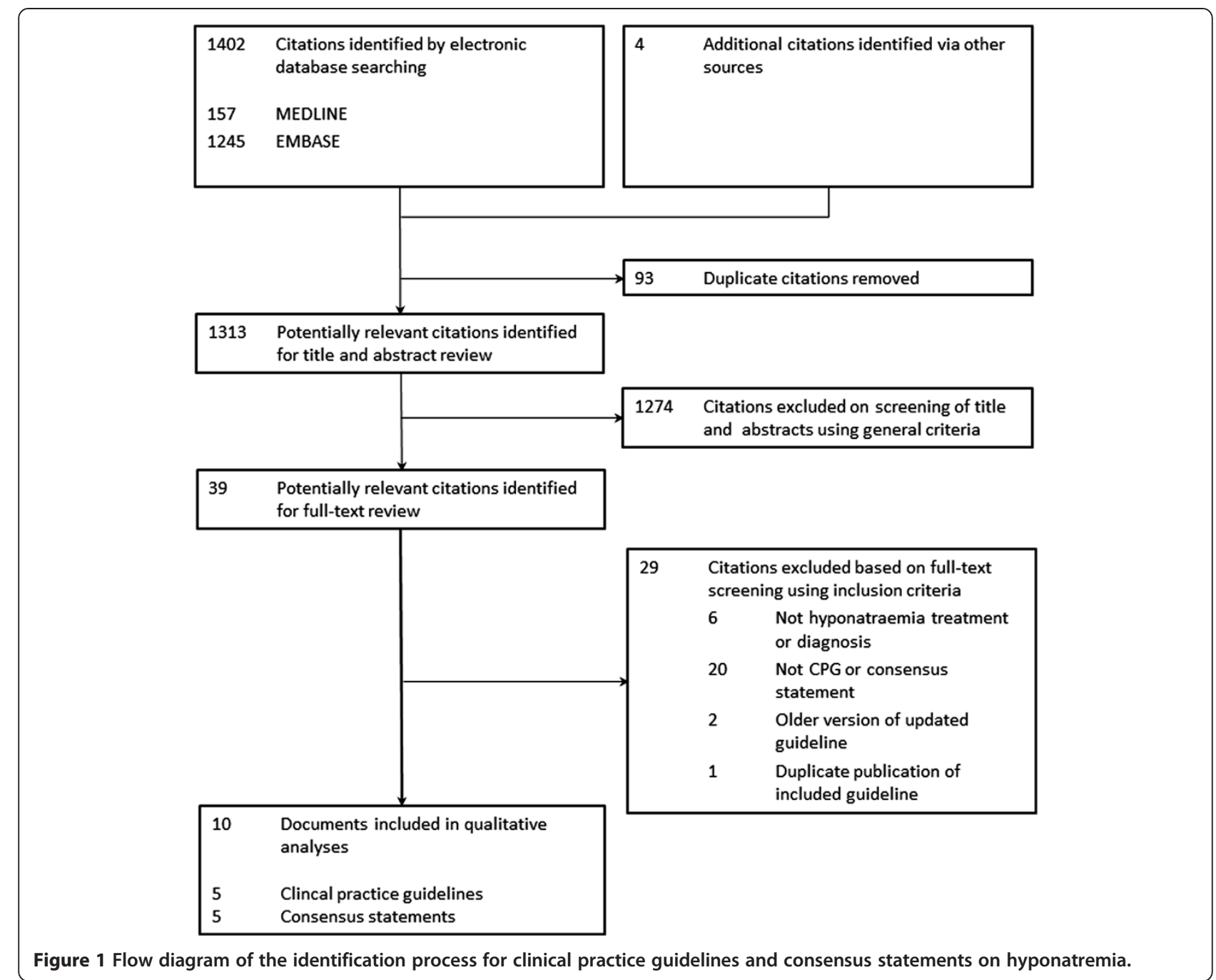

documents between domains. Overall, guideline developers reported the details of the guideline development process only to a limited extent. Most had average scores below $50 \%$ in four to six of the six AGREE II domains $[17,19,21-25]$, only two received an average $>50 \%$ on all six $[16,20]$.

Guidelines received the highest scores for scope and purpose (median 62\%; range $28 \%$ to $92 \%$ ) and clarity of presentation (median 47\%; range $27 \%$ to $75 \%$ ), and lowest scores for applicability (median 19\%; range 10\% to $68 \%$ ) and editorial independence (median 19\%; range $2 \%$ to $79 \%)$.

Initial appraisal results differed more than one point on the Likert scale between two or more reviewers for $143 / 230$ items (62\%). The majority of discrepancies were found in the domain Clarity of Presentation, with 90\% of items differing more than one point. Group discussion resulted in 287/920 (31\%) of individual entries being changed. Finally, no scores differed more than two points and for $82 \%$ of items, scores were the same or within one point of each other. Major reasons for changing an entry were a change of own opinion after clarification of the opinion of other reviewers during the group discussion (180/920 entries; $20 \%$ entries); aiming for consistency between entries given same available data (39/920; 4\%); re-evaluation of the score in light of a noted comment during the appraisal process (30/920; $3 \%)$; correction for available data that were overlooked during the initial appraisal (22/920; 2\%); misinterpretation of the question during the initial appraisal (6/920; $0.7 \%$ ); adjusting for arbitrary scoring of items that were felt to be inapplicable for some reason $(3 / 920 ; 0.3 \%)$; adjusting for inconsistent approach to deal with the assumption that a criterion was fulfilled even if this was not clearly mentioned (4/920;0.4\%); and data entry error (3/920, 0.3\%). Overall, this resulted in $29 / 60$ (48\%) of standardized domain scores being downgraded by a maximum of $10 \%$ and 10/60 (17\%) of standardized domain scores being upgraded with a maximum of $10 \%$; the remaining $35 \%$ remained unchanged. 
Table 1 Characteristics of included guidelines and consensus statements

\begin{tabular}{|c|c|c|c|c|c|c|c|c|c|c|}
\hline Developer & Year & Country & $\begin{array}{l}\text { Funding } \\
\text { source }\end{array}$ & $\begin{array}{l}\text { Target } \\
\text { population }\end{array}$ & $\begin{array}{l}\text { Target } \\
\text { users }\end{array}$ & $\begin{array}{l}\text { Guideline } \\
\text { writers }\end{array}$ & $\begin{array}{l}\text { Guideline } \\
\text { review }\end{array}$ & $\begin{array}{l}\text { Guideline } \\
\text { update }\end{array}$ & $\begin{array}{l}\text { Methods } \\
\text { support }\end{array}$ & $\begin{array}{l}\text { Evidence } \\
\text { base }\end{array}$ \\
\hline \multicolumn{11}{|l|}{ Europe } \\
\hline NIV & 2012 & Netherlands & $\begin{array}{l}\text { Government } \\
\text { funding }\end{array}$ & $\begin{array}{l}\text { Adults with } \\
\text { hyponatremia }\end{array}$ & $\begin{array}{l}\text { Clinicians, } \\
\text { Internists }\end{array}$ & $\begin{array}{l}\text { Multidisciplinary } \\
\text { internists, } \\
\text { epidemiologist }\end{array}$ & $\begin{array}{l}\text { Dutch Association } \\
\text { of Internists (NIV), } \\
\text { expert peer review }\end{array}$ & $\begin{array}{l}\text { In case of } \\
\text { breakthrough } \\
\text { changes in } \\
\text { diagnosis or } \\
\text { treatment }\end{array}$ & $\begin{array}{l}\text { PROVA company } \\
\text { specialized in } \\
\text { Evidence Based } \\
\text { Guideline } \\
\text { Development }\end{array}$ & $\begin{array}{l}\text { Systematic } \\
\text { literature } \\
\text { review }\end{array}$ \\
\hline NHS & 2011 & UK & NS & $\begin{array}{l}\text { Adults with } \\
\text { hyponatremia in } \\
\text { primary care }\end{array}$ & $\begin{array}{l}\text { Primary care } \\
\text { professionals } \\
\text { within NHS }\end{array}$ & NS & NS & $\begin{array}{l}\text { Planned } \\
\text { in } 2015\end{array}$ & NS & $\begin{array}{l}\text { Systematic } \\
\text { literature } \\
\text { review }\end{array}$ \\
\hline GAIN* & 2010 & $\begin{array}{l}\text { Northern } \\
\text { Ireland }\end{array}$ & $\begin{array}{l}\text { Government } \\
\text { funding }\end{array}$ & $\begin{array}{l}\text { Adults with } \\
\text { hyponatremia }\end{array}$ & NS & $\begin{array}{l}\text { Multidisciplinary } \\
\text { anesthetists, clinical } \\
\text { chemist, nephrologist }\end{array}$ & NS & 3 years & NS & NS \\
\hline $\mathrm{AEEH}^{*}$ & $\begin{array}{l}2003- \\
2004\end{array}$ & Spain & NS & Patients with cirrhosis & NS & Gastroenterologists & NS & NS & NS & NS \\
\hline$E H N^{*}$ & 2013 & Spain & NS & $\begin{array}{l}\text { Hospitalized patients } \\
\text { with SIADH }\end{array}$ & NS & $\begin{array}{l}\text { Multidisciplinary } \\
\text { endocrinologists, } \\
\text { nephrologists, internists, } \\
\text { hospital pharmacist }\end{array}$ & NS & NS & NS & $\begin{array}{l}\text { Consensus } \\
\text { statements }\end{array}$ \\
\hline $\begin{array}{l}\text { ERBP/ESE/ } \\
\text { ESICM }\end{array}$ & 2014 & Europe & $\begin{array}{l}\text { Unrestricted } \\
\text { grant from } \\
\text { participating } \\
\text { societies }\end{array}$ & $\begin{array}{l}\text { Adults with } \\
\text { hyponatremia }\end{array}$ & $\begin{array}{l}\text { Health care } \\
\text { professionals } \\
\text { dealing with } \\
\text { hyponatremia }\end{array}$ & $\begin{array}{l}\text { Multidisciplinary } \\
\text { nephrologists, } \\
\text { endocrinologists, } \\
\text { general internists, } \\
\text { critical care physicians }\end{array}$ & $\begin{array}{l}\text { External review by } \\
\text { KHA-CARI, ESA, and } \\
\text { members ERA-EDTA }\end{array}$ & $\begin{array}{l}5 \text { years or } \\
\text { earlier in } \\
\text { case of new } \\
\text { evidence } \\
\text { requiring } \\
\text { changes }\end{array}$ & $\begin{array}{l}\text { ERBP methods } \\
\text { support team }\end{array}$ & $\begin{array}{l}\text { Systematic } \\
\text { literature } \\
\text { review }\end{array}$ \\
\hline \multicolumn{11}{|l|}{$\begin{array}{l}\text { North } \\
\text { America }\end{array}$} \\
\hline UF & $\begin{array}{l}2008- \\
2009\end{array}$ & USA & NS & $\begin{array}{l}\text { Neurosurgery patients } \\
\text { with hyponatremia }\end{array}$ & NS & $\begin{array}{l}\text { Multidisciplinary } \\
\text { neurosurgeons, nurse } \\
\text { practitioners, nephrologists, } \\
\text { critical care physician, } \\
\text { endocrinologist, } \\
\text { pharmacist, nurses }\end{array}$ & NS & NS & NS & $\begin{array}{l}\text { Systematic } \\
\text { literature } \\
\text { review }\end{array}$ \\
\hline HEP & 2013 & USA & $\begin{array}{l}\text { Funding } \\
\text { Unrestricted } \\
\text { educational } \\
\text { grant from } \\
\text { pharmaceutical } \\
\text { company }\end{array}$ & $\begin{array}{l}\text { Patients with } \\
\text { hyponatremia }\end{array}$ & NS & $\begin{array}{l}\text { Endocrinologist, } \\
\text { nephrologists }\end{array}$ & NS & NS & NS & $\begin{array}{l}\text { Systematic } \\
\text { literature } \\
\text { review }\end{array}$ \\
\hline \multicolumn{11}{|l|}{ Australia } \\
\hline $\mathrm{RCHM}^{*}$ & 2012 & Australia & NS & Children & NS & NS & $\begin{array}{l}\text { External review } \\
\text { within the hospital } \\
\text { where appropriate }\end{array}$ & $\begin{array}{l}12 \text { to } \\
24 \text { months }\end{array}$ & NS & NS \\
\hline
\end{tabular}


Table 1 Characteristics of included guidelines and consensus statements (Continued)

\section{International}

EAH- ICD*

\begin{tabular}{|c|c|c|c|}
\hline 2007 & $\begin{array}{l}\text { USA, Canada, } \\
\text { UK, Switzer-land, } \\
\text { Canada, South } \\
\text { Africa, New }\end{array}$ & $\begin{array}{l}\text { No commercial } \\
\text { sponsorship }\end{array}$ & $\begin{array}{l}\text { People with } \\
\text { exercise-associated } \\
\text { hyponatremia }\end{array}$ \\
\hline
\end{tabular}

$$
\begin{array}{ll}
\begin{array}{l}
\text { Medical } \\
\text { personnel, }
\end{array} & \text { Multidisciplinary } \\
\text { athletes, } & \text { endocrinologist, } \\
\text { greater public } & \text { epidemiologist, } \\
& \text { nephrologists, } \\
& \text { phergency medicine } \\
& \text { practian, general } \\
& \text { sports physicians, } \\
& \text { exercise physiologists }
\end{array}
$$

NS

NIV Nederlandse Internisten Vereniging [16]; NHS, National Health Service [17]; GAIN, Guidelines and Audit Implementation Network [22]; AEEH La Asociacin Espaola para el Estudio del Hgado [ 23]; EHN, European Hyponatremia Network [25]; ERBP, European Renal Best Practice; ESE, European Society of Endocrinology; ESICM, European Society of Intensive Care Medicine [20]; UF, University of Florida [18]; HEP, Hyponatremia Expert Panel [19]; RCH Melbourne, the Royal Children s Hospital Melbourne [21]; EAH-ICD, International Exercise-Associated Hyponatremia Consensus Development Conference [24]; [Na], Serum sodium concentration; NS, Not stated; KHA-CARI, Kidney Health Australia, Caring for Australasians with Renal Impairment; ESA, Endocrine Society of Australia; ERA-EDTA, European Renal Association; European Dialysis and Transplant Association; *Classified as consensus statement. 


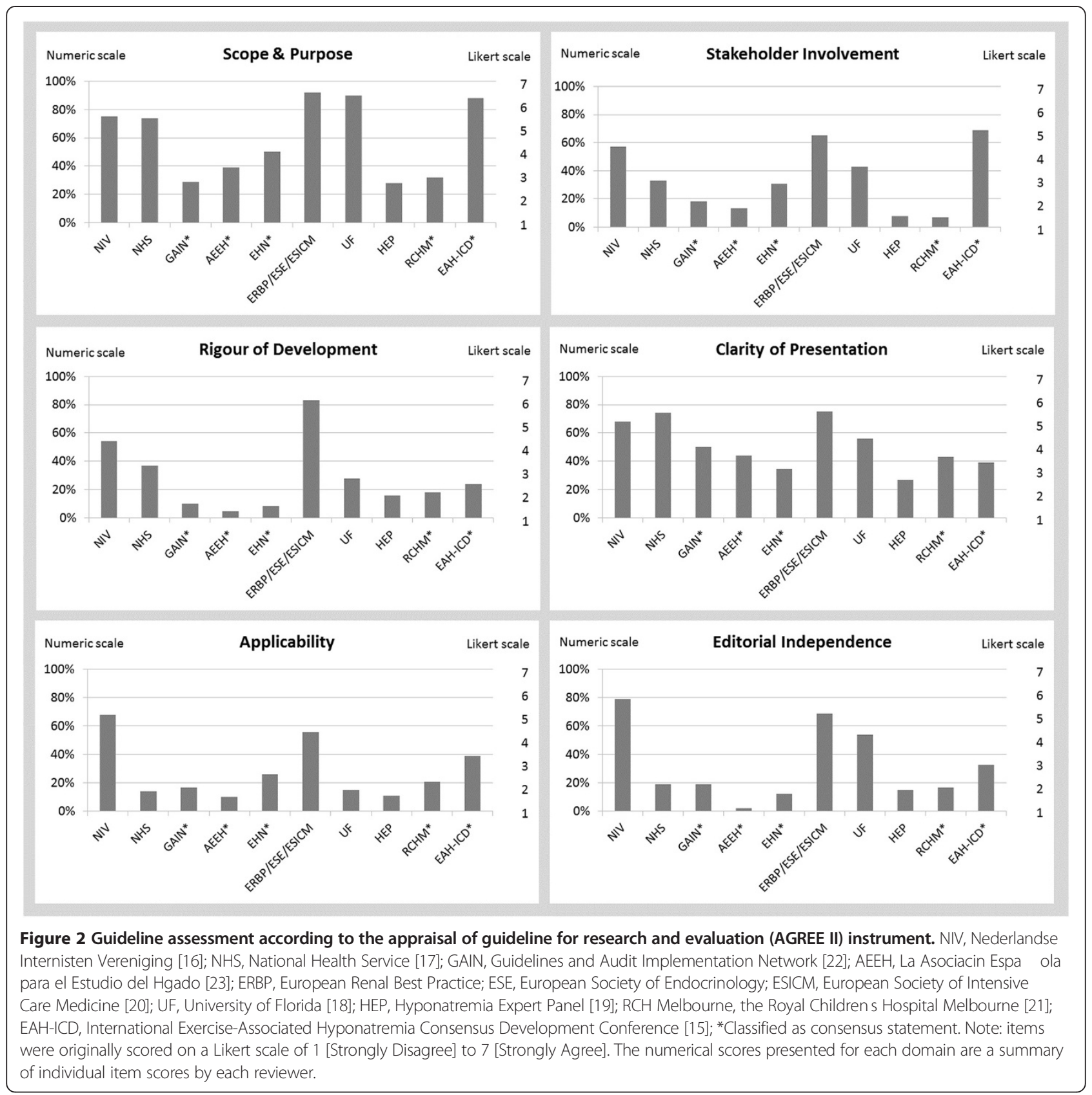

\section{Synthesis of recommendations}

The included guidance documents addressed three major themes: diagnosis, treatment, and speed of correction.

\section{Approaches to diagnostic strategies for hyponatremia}

Seven guidance documents covered diagnosis and differential diagnosis of hyponatremia [16-22]. Table 2 shows the key recommendations. The key areas addressed included the threshold for initiating diagnostic workup, confirmation and classification of hypotonic hyponatremia, and identification of the underlying disorder.
Guidance documents differed somewhat in their recommended threshold for starting diagnostic assessment. Six recommended starting diagnostic assessment when the serum sodium concentration dropped below $135 \mathrm{mmol} / \mathrm{L}$ [17,19-23] and to confirm hypotonicity through a measured serum or plasma osmolality $<275$ to $285 \mathrm{mOsm} / \mathrm{kg}$ [16-20,22]. Two others set lower thresholds of serum sodium concentration at $<131 \mathrm{mmol} / \mathrm{L}[18]$ and $<130 \mathrm{mmol} / \mathrm{L}$ [23]. Six guidance documents advised classifying hypotonic hyponatremia into categories of hypovolemia, euvolemia, and hypervolemia to aid differential diagnosis and guide treatment [16-22]. Most guidance documents recom- 
Table 2 Summary of recommendations for approaches to diagnosis of hyponatremia by included guidance documents

\begin{tabular}{|c|c|c|c|c|c|c|c|c|c|c|}
\hline \multirow[b]{2}{*}{ Criteria/Categories } & \multicolumn{10}{|c|}{ Guideline Organization/Society } \\
\hline & NIV [16] & NHS [17] & GAIN [22] & AEEH [23] & EHN [25] & $\begin{array}{l}\text { ERBP/ESE/ } \\
\text { ESICM [20] }\end{array}$ & UF [18] & HEP [19] & RCHM [21] & $\begin{array}{l}\text { EAH-ICD } \\
{[24]}\end{array}$ \\
\hline Threshold workup [Na] & $<135 \mathrm{mmol} / \mathrm{L}$ & $<135 \mathrm{mmol} / \mathrm{L}$ & $<135 \mathrm{mmol} / \mathrm{L}$ & $<130 \mathrm{mmol} / \mathrm{L}$ & $<135 \mathrm{mmol} / \mathrm{L}$ & $<135 \mathrm{mmo} / \mathrm{L}$ & $<131 \mathrm{mmo} / \mathrm{L}$ & $<135 \mathrm{mmol} / \mathrm{L}$ & $<135 \mathrm{mmol} / \mathrm{L}$ & \\
\hline $\begin{array}{l}\text { Confirming hypotonic } \\
\text { hyponatremia }\end{array}$ & $\begin{array}{l}\text { Serum osmolality } \\
<275 \text { mOsm/kg }\end{array}$ & $\begin{array}{l}\text { Plasma osmolality } \\
<280 \mathrm{mOsm} / \mathrm{kg}\end{array}$ & $\begin{array}{l}\text { Serum osmolality } \\
<275 \text { mOsm/kg }\end{array}$ & & $\begin{array}{l}\text { Plasma osmolality } \\
<275 \mathrm{mOsm} / \mathrm{kg}\end{array}$ & $\begin{array}{l}\text { Serum osmolality } \\
<275 \mathrm{mOsm} / \mathrm{kg}\end{array}$ & $\begin{array}{l}\text { Serum osmolality } \\
<285 \mathrm{mOsm} / \mathrm{kg}\end{array}$ & $\begin{array}{l}\text { Plasma osmolality } \\
<280 \mathrm{mOsm} / \mathrm{kg}\end{array}$ & $\begin{array}{l}\text { Serum } \\
\text { osmolality } \\
\text { threshold } \\
\text { not stated }\end{array}$ & \\
\hline \multicolumn{11}{|l|}{$\begin{array}{l}\text { How to classify } \\
\text { hypotonic hyponatremia } \\
\text { to aid identification of } \\
\text { underlying cause }\end{array}$} \\
\hline $\begin{array}{l}\text { Volume status/ } \\
\text { hydration state/ } \\
\text { extracellular fluid } \\
\text { status }\end{array}$ & $\begin{array}{l}\text { Clinical } \\
\text { evaluation }\end{array}$ & $\begin{array}{l}\text { Physical } \\
\text { examination/clinical } \\
\text { signs of dehydration } \\
\text { or edema }\end{array}$ & $\begin{array}{l}\text { Physical } \\
\text { examination/clinical } \\
\text { signs of dehydration } \\
\text { or edema }\end{array}$ & & $\begin{array}{l}\text { Physical } \\
\text { examination/ } \\
\text { clinical signs of } \\
\text { low circulating } \\
\text { volume }\end{array}$ & $\begin{array}{l}\text { Physical } \\
\text { examination/ } \\
\text { clinical signs of } \\
\text { dehydration } \\
\text { or edema }\end{array}$ & $\begin{array}{l}\text { Physical } \\
\text { examination/ } \\
\text { laboratory } \\
\text { measurements }\end{array}$ & $\begin{array}{l}\text { Physical } \\
\text { examination/ } \\
\text { laboratory } \\
\text { measurements }\end{array}$ & $\begin{array}{l}\text { To assess } \\
\text { but method } \\
\text { not stated }\end{array}$ & \\
\hline Urinary $[\mathrm{Na}] /$ Threshold & $30 \mathrm{mmol} / \mathrm{L}$ & $\begin{array}{l}\text { Spot urine: } \\
2030 \mathrm{mmol} / \mathrm{L}\end{array}$ & $15 \mathrm{mmol} / \mathrm{L}$ & & $40 \mathrm{mmol} / \mathrm{L}$ & $30 \mathrm{mmol} / \mathrm{L}$ & $25 \mathrm{mmol} / \mathrm{L}$ & $\begin{array}{l}\text { Spot urine: } \\
2030 \mathrm{mmol} / \mathrm{L}\end{array}$ & $\begin{array}{l}\text { No threshold } \\
\text { stated }\end{array}$ & \\
\hline $\begin{array}{l}\text { Urinary osmolality/ } \\
\text { Threshold }\end{array}$ & $100 \mathrm{mOsm} / \mathrm{kg}$ & 100 mOsm/kg & $100 \mathrm{mOsm} / \mathrm{kg}$ & & $100 \mathrm{mOsm} / \mathrm{kg}$ & 100 mOsm/kg & 100 mOsm/kg & 100 mOsm/kg & $\begin{array}{l}\text { No threshold } \\
\text { stated }\end{array}$ & \\
\hline \multicolumn{11}{|l|}{$\begin{array}{l}\text { How to identify the } \\
\text { underlying disorder }\end{array}$} \\
\hline \multirow[t]{3}{*}{ History } & & Medications & Medications & & & Diuretic use & & & & \\
\hline & & Fluid intake & $\begin{array}{l}\text { Recently prescribed } \\
\text { intravenous fluids }\end{array}$ & & & & & & & \\
\hline & & Nocturnal polyuria & Vomiting/diarrhea & & & & & & & \\
\hline \multicolumn{11}{|l|}{ Lab tests } \\
\hline $\begin{array}{l}\text { Serum potassium } \\
\text { concentration }\end{array}$ & + & + & & & & & & & + & \\
\hline $\begin{array}{l}\text { Serum chloride } \\
\text { concentration }\end{array}$ & & + & & & & & & & + & \\
\hline $\begin{array}{l}\text { Serum urea } \\
\text { concentration }\end{array}$ & +1 & + & & & & & +1 & +1 & + & \\
\hline $\begin{array}{l}\text { Serum creatinine } \\
\text { concentration }\end{array}$ & + & + & & & & & +1 & +1 & + & \\
\hline $\begin{array}{l}\text { Serum glucose } \\
\text { concentration }\end{array}$ & + & + & +1 & & & + & & & + & \\
\hline
\end{tabular}


Table 2 Summary of recommendations for approaches to diagnosis of hyponatremia by included guidance documents (Continued)

\begin{tabular}{|c|c|c|c|c|c|}
\hline \multirow[t]{2}{*}{$\begin{array}{l}\text { Urinary potassium } \\
\text { concentration }\end{array}$} & \multicolumn{2}{|l|}{+} & & \multicolumn{2}{|l|}{+} \\
\hline & & & + & & \\
\hline Liver tests & & & + & $+/$ & \\
\hline Urinary protein & & +1 & & & \\
\hline $\begin{array}{l}\text { Thyroid function } \\
\text { tests }\end{array}$ & +1 & +1 & $+/$ & +1 & \\
\hline $\begin{array}{l}\text { Adrenal function } \\
\text { tests }\end{array}$ & +1 & +1 & +1 & $+/$ & \\
\hline $\begin{array}{l}\text { Serum protein } \\
\text { electrophoresis }\end{array}$ & & +1 & & & \\
\hline $\begin{array}{l}\text { Urine protein } \\
\text { electrophoresis }\end{array}$ & & +1 & & & \\
\hline $\begin{array}{l}\text { Fractional sodium } \\
\text { excretion }\end{array}$ & +1 & & & & \\
\hline $\begin{array}{l}\text { Serum uric acid } \\
\text { concentration }\end{array}$ & +1 & +1 & & + & +1 \\
\hline $\begin{array}{l}\text { Fractional uric acid } \\
\text { concentration }\end{array}$ & +1 & & & & \\
\hline $\begin{array}{l}\text { Fractional excretion } \\
\text { urea }\end{array}$ & +1 & & & & \\
\hline $\begin{array}{l}\text { Urinary chloride } \\
\text { concentration }\end{array}$ & +1 & & & + & +1 \\
\hline Molar weight urine & +1 & & & & \\
\hline $\begin{array}{l}\text { Serum bicarbonate } \\
\text { concentration }\end{array}$ & & & & $+/$ & \\
\hline Hematocrit & & & & +1 & \\
\hline
\end{tabular}

[Na], Serum sodium concentration; +, always; + / , If clinically indicated/sometimes useful.

NIV, Nederlandse Internisten Vereniging [16]; NHS, National Health Service [17]; GAIN, Guidelines and Audit Implementation Network [22]; AEEH, La Asociacin Espaola para el Estudio del Hgado [ 23]; EHN, European

Hyponatremia Network [25]; ERBP, European Renal Best Practice; ESE, European Society of Endocrinology; ESICM, European Society of Intensive Care Medicine [20]; UF, University of Florida [18]; HEP, Hyponatremia

Expert Panel [19]; RCH Melbourne, the Royal Children s Hospital Melbourne [21]; EAH-ICD, International Exercise-Associated Hyponatremia Consensus Development Conference [24]. 
mended a clinical assessment of hydration status and a urinary sodium concentration as well as a urinary osmolality measurement, although specific criteria, thresholds, and algorithms differed.

Most guidance documents proposed additional laboratory tests that could be of value to identify the underlying disorder, but they varied substantially regarding which tests to use in what situation and which reference values to use. Only two explicitly recommended taking a history of drug intake and symptoms as part of the assessment $[17,22]$. Four presented an algorithm to guide differential diagnosis [16,18,20,22].

\section{Approaches to treatment for hyponatremia}

Table 3 shows the recommendations for the medical management of hyponatremia. Guidance documents distinguished treatment scenarios based on whether patients had severe symptoms [17-22,24,25] or whether the hyponatremia was acute $(48 \mathrm{~h})$ or chronic [16]. All but one discussed treatment in the setting of severe symptoms and recommended infusion of hypertonic saline, usually specified as having a concentration of $3 \%[17,19-21,24,25]$. One suggested using a formula to guide the infusion speed of a continuous infusion [16], five others recommended giving a fixed dose [19,20,22,24,25], or a dose adjusted to body weight $[21,25]$ with repeated serum sodium concentration measurements to check progression [16,20-22,25].

Patients without symptoms of hyponatremia were assumed to have chronic onset hyponatremia, and treatment suggestions were mostly dependent on the classification hypovolemic, euvolemic, or hypervolemic. Only three guidance documents specifically advised treating the underlying condition [19,22]. Seven suggested $0.9 \%$ saline in hypovolemia [16-22], with infusion speeds calculated with Adrogu-Madias [22], until restoration of blood pressure $[17,19]$ or until nasogastric rehydration could start [21].

For euvolemic asymptomatic hyponatremia, the majority recommended fluid restriction as the first-line treatment [16-25]. Five guidance documents proposed a number of other interventions as second-line treatments including loop diuretics $[16,18,20,25]$, demeclocycline [16-19], urea $[16,19,20,25]$, vasopressin receptor antagonists $[16,17,25]$, or lithium [18]. One guideline specifically recommended against vasopressin receptor antagonists in case of a serum sodium concentration $<125 \mathrm{mmol} / \mathrm{L}$ [20].

For hypervolemic asymptomatic hyponatremia, seven guidance documents recommended fluid restriction as the first-line treatment $[16,17,19-23]$ (Table 3). Three guidance documents advocated concomitant salt restriction, without clear dose recommendations $[17,19,22]$, and one to avoid hypotonic infusion solution [21]. Three additionally proposed loop diuretics $[16,17,19]$ and three others generally stated to treat the underlying disease [17,20,22], whereas one advised to consider stopping diuretics [23]. One guideline additionally proposed demeclocycline and two proposed vasopressin receptor antagonists as a secondline treatment for refractory hyponatremia $[17,19]$, whereas one guideline specifically recommended against both demeclocycline and vasopressin receptor antagonists [20].

\section{Targets and limits of speed of correction}

Table 4 shows the key recommendations. The key areas include targets and limits for increase in serum sodium concentration.

Seven guidance documents provided targets or aims for the increase in serum sodium concentration in case of symptomatic and/or acute hyponatremia [16,17,19-22,25]. Seven guidance documents provided limits for the increase in serum sodium concentration that should not be surpassed [16-22,25]. Five did so independent of symptoms [16,18,20,22,25]. Limits usually varied between 8 to $12 \mathrm{mmol} / \mathrm{L}$ during the first 24 hours [16-22,25] and $18 \mathrm{mmol} / \mathrm{L}$ during the first 48 hours $[16,17,19,20,25]$, irrespective of whether hyponatremia was acute or chronic $[16,17,20,25]$. Three guidance documents set a stricter limit of $<8 \mathrm{mmol} / \mathrm{L}$ during the first 24 hours in cases where the patient was believed to be high risk for developing osmotic demyelination syndrome $[16,19,25]$. Four discussed what to do in case of overcorrection, i.e., to stop current treatment and to consider re-lowering serum sodium concentration by starting hypotonic infusion and administering 1 to $4 \mu \mathrm{g}$ desmopressin every 6 to 8 hours $[16,19,20,25]$.

\section{Discussion}

We found five clinical practice guidelines and five consensus statements covering the diagnostic approach to and treatment of hyponatremia. Although most used serum osmolality, volume status, urinary sodium, and urinary osmolality to guide differential diagnosis, they differed in classification thresholds, what additional tests to consider, and when to initiate diagnostic work-up. Most advocated hypertonic $\mathrm{NaCl}$ in severely symptomatic, acute onset hyponatremia and $\mathrm{NaCl} 0.9 \%$, fluid restriction, and cause-specific therapy for hypovolemic, euvolemic, and hypervolemic hyponatremia, respectively. However, they somewhat differed in the limits for speed of increase in serum sodium concentration and which specific medications to use. The reasons for offering different recommendations are undoubtedly multifactorial. They may in part be explained by the fact that recommendations were issued by organizations differing in context and scope. It is also very likely that some variability in guidance arose through limitations in the evidence available for guideline developers to base their recommendations on [8]. In the most recent guideline on diagnosis and treatment of hyponatremia, $98 \%$ of the 
Table 3 Summary of recommendations for approaches to treatments for hyponatremia by included guidance documents

\begin{tabular}{|c|c|c|c|c|c|c|c|c|c|c|}
\hline \multirow[b]{2}{*}{$\begin{array}{l}\text { Criteria/ } \\
\text { categories }\end{array}$} & \multicolumn{10}{|c|}{ Guideline Organization/Societies } \\
\hline & NIV [16] & NHS [17] & GAIN [22] & AEEH [23] & EHN [25] & $\begin{array}{l}\text { ERBP/ESE/ } \\
\text { ESICM [20] }\end{array}$ & UF [18] & HEP [19] & $\mathrm{RCHM}[21]$ & $\begin{array}{l}\text { EAH-ICD } \\
{[24]}\end{array}$ \\
\hline \multicolumn{11}{|l|}{ Symptoms } \\
\hline $\begin{array}{l}\text { Acute Onset } \\
(<48 \mathrm{~h})\end{array}$ & $\begin{array}{l}\mathrm{NaCl}>1 \% \\
\text { Infusion speed } \\
\text { may be guided by } \\
\text { Adrogu-Madias }\end{array}$ & $\mathrm{NaCl} 3 \%$ & $\begin{array}{l}\mathrm{NaCl} 2.7 \% \\
200 \mathrm{~mL} \text { over } \\
30 \mathrm{~min}\end{array}$ & & $\begin{array}{l}\mathrm{NaCl} 3 \% 100 \mathrm{~mL} / \\
10 \text { min up to } \\
3 \text { or infused at } \\
0.52 \mathrm{~mL} / \mathrm{kg} / \mathrm{h}\end{array}$ & $\begin{array}{l}\mathrm{NaCl} 3 \% 150 \mathrm{~mL} / \\
20 \text { min up to } 4\end{array}$ & $\mathrm{NaCl}>1 \%$ & $\begin{array}{l}\mathrm{NaCl} 3 \% 100 \mathrm{~mL} / \\
10 \text { min up to } \\
3 \text { or infused at } \\
0.52 \mathrm{~mL} / \mathrm{kg} / \mathrm{h}\end{array}$ & $\begin{array}{l}\mathrm{NaCl} 3 \% \\
4 \mathrm{~mL} / \mathrm{kg} \\
\text { over } 30 \text { min }\end{array}$ & $\begin{array}{l}\mathrm{NaCl} 3 \% \\
100 \mathrm{~mL} \\
\text { bolus }\end{array}$ \\
\hline Hypovolemia & & & & & & & & $\begin{array}{l}\mathrm{NaCl} 0.9 \% \text { until } \\
\text { blood pressure } \\
\text { restored }\end{array}$ & & \\
\hline \multirow[t]{3}{*}{ Euvolemia } & & & Fluid restriction & & & & & & & $\begin{array}{l}\text { No } \\
\text { hypotonic } \\
\text { fluids }\end{array}$ \\
\hline & & & $\begin{array}{l}\text { Stop offending } \\
\text { drugs }\end{array}$ & & & & & & & \\
\hline & & & $\begin{array}{l}\text { Stop hypotonic } \\
\text { fluids }\end{array}$ & & & & & & & \\
\hline Hypervolemia & & & Furosemide & & & & & Furosemide & & \\
\hline $\begin{array}{l}\text { Chronic onset } \\
(>48 \mathrm{~h})\end{array}$ & $\begin{array}{l}\mathrm{NaCl}>1 \% \text { Infusion } \\
\text { speed calculation } \\
\text { may be guided by } \\
\text { Adrogu-Madias }\end{array}$ & $\mathrm{NaCl} 3 \%$ & $\begin{array}{l}\text { Only if severe } \\
\text { symptoms } \mathrm{NaCl} 2.7 \% \\
200 \mathrm{~mL} \text { over } 30 \mathrm{~min} \\
\text { infusion speed by } \\
\text { may be guided } \\
\text { Adrogu-Madias }\end{array}$ & & $\begin{array}{l}\mathrm{NaCl} 3 \% 100 \mathrm{~mL} / \\
10 \text { min up to } \\
3 \text { or infused at } \\
0.52 \mathrm{~mL} / \mathrm{kg} / \mathrm{h}\end{array}$ & $\begin{array}{l}\mathrm{NaCl} 3 \% 150 \mathrm{~mL} / \\
20 \text { min up to } 4\end{array}$ & $\mathrm{NaCl}>1 \%$ & $\begin{array}{l}\mathrm{NaCl} 3 \% 100 \mathrm{~mL} / \\
10 \text { min up to } 3 \\
\text { or infused at } \\
0.5-2 \mathrm{~mL} / \mathrm{kg} / \mathrm{h}\end{array}$ & & \\
\hline Hypovolemia & & & $\begin{array}{l}\mathrm{NaCl} 0.9 \% 1 \mathrm{~L} \text { over } \\
24 \mathrm{~h} \text { infusion speed } \\
\text { may be guided by } \\
\text { Adrogu-Madias }\end{array}$ & & & & & $\begin{array}{l}\mathrm{NaCl} 0.9 \% \text { until } \\
\text { blood pressure } \\
\text { restored }\end{array}$ & & \\
\hline \multirow[t]{3}{*}{ Euvolemia } & & & Fluid restriction & & & & & & & \\
\hline & & & $\begin{array}{l}\text { Stop offending } \\
\text { medications }\end{array}$ & & & & & & & \\
\hline & & & $\begin{array}{l}\text { Stop hypotonic } \\
\text { fluids }\end{array}$ & & & & & & & \\
\hline \multirow[t]{2}{*}{ Hypervolemia } & & & Fluid restriction & & & & & Furosemide & & \\
\hline & & & Salt restriction & & & & & & & \\
\hline \multicolumn{11}{|l|}{ No symptoms } \\
\hline $\begin{array}{l}\text { Acute onset } \\
(<48 \mathrm{~h})\end{array}$ & $\begin{array}{l}\mathrm{NaCl}>1 \% \\
\text { Infusion speed by } \\
\text { Adrogu-Madias }\end{array}$ & & $\begin{array}{l}\text { Treat underlying } \\
\text { condition }\end{array}$ & & & $\begin{array}{l}\text { Stop offending fluids } \\
\text { and medications, } \\
\text { treat underlying }\end{array}$ & & $\begin{array}{l}\text { Treat underlying } \\
\text { condition }\end{array}$ & & \\
\hline
\end{tabular}


Table 3 Summary of recommendations for approaches to treatments for hyponatremia by included guidance documents (Continued)

\begin{tabular}{|c|c|c|c|c|c|c|c|c|c|}
\hline & & & & & & $\begin{array}{l}\text { condition NaCl } \\
3 \% 150 \mathrm{~mL} / 20 \mathrm{~min}\end{array}$ & & & \\
\hline $\begin{array}{l}\text { Chronic } \\
\text { onset ( }>48 \mathrm{~h} \text { ) }\end{array}$ & $\begin{array}{l}\text { Treat underlying } \\
\text { condition }\end{array}$ & & $\begin{array}{l}\text { Treat underlying } \\
\text { condition }\end{array}$ & & & $\begin{array}{l}\text { Stop non-essential } \\
\text { fluids Stop offending } \\
\text { medications Treat } \\
\text { underlying condition }\end{array}$ & & $\begin{array}{l}\text { Treat underlying } \\
\text { condition }\end{array}$ & \\
\hline \multirow[t]{2}{*}{ Hypovolemia } & $\mathrm{NaCl} 0.9 \%$ & $\begin{array}{l}\mathrm{NaCl} 0.9 \% \text { until } \\
\text { blood pressure } \\
\text { restored }\end{array}$ & $\begin{array}{l}\mathrm{NaCl} 0.9 \% \\
\text { infusion speed } \\
\text { may be guided by } \\
\text { Adrogu-Madias }\end{array}$ & & & $\begin{array}{l}\mathrm{NaCl} 0.9 \% \text { or } \\
\text { balanced crystalloid } \\
0.51 \mathrm{~mL} / \mathrm{kg} / \mathrm{h}\end{array}$ & $\mathrm{NaCl} 0.9 \%$ & $\begin{array}{l}\mathrm{NaCl} 0.9 \% \text { until } \\
\text { blood pressure } \\
\text { restored }\end{array}$ & $\begin{array}{l}\text { Nasogastric } \\
\text { rehydration }\end{array}$ \\
\hline & $\mathrm{NaCl}$ tablets & & & & & & & No VPA & $\mathrm{NaCl} 0.9 \%$ \\
\hline \multirow[t]{6}{*}{ Euvolemia } & $\begin{array}{l}\text { Fluid restriction, } \\
\text { dose dependent } \\
\text { on serum and } \\
\text { urinary electrolytes }\end{array}$ & $\begin{array}{l}\text { Fluid restriction, } \\
5001,000 \mathrm{~mL} / \mathrm{d}\end{array}$ & Fluid restriction & & $\begin{array}{l}\text { Fluid restriction } \\
<500 \quad 1,000 \mathrm{~mL} / \mathrm{d}\end{array}$ & Fluid restriction & Fluid restriction & $\begin{array}{l}\text { Fluid restriction } \\
500 \mathrm{~mL} \text { below } \\
\text { average daily } \\
\text { urine output }\end{array}$ & $\begin{array}{l}\text { Fluid restriction, } \\
\text { no hypotonic } \\
\text { fluids }\end{array}$ \\
\hline & & $\begin{array}{l}\text { No salt } \\
\text { restriction }\end{array}$ & Salt restriction & & Salt $58 \mathrm{~g} / \mathrm{d}$ & & & No salt restriction & \\
\hline & Loop diuretics & & & & $\begin{array}{l}\text { Furosemide } \\
2060 \mathrm{mg} / \mathrm{d}+ \\
\text { oral } \mathrm{NaCl}\end{array}$ & $\begin{array}{l}\text { Loop diuretics, } \\
\text { low dose }+ \\
\text { oral } \mathrm{NaCl}\end{array}$ & Diuretics & & \\
\hline & Demeclocycline & Demeclocycline & & & & No demeclocycline & Demeclocycline & $\begin{array}{l}\text { Demeclocycline, } \\
600 \quad 1,200 \mathrm{mg} / \mathrm{d}\end{array}$ & \\
\hline & Urea & & & & Urea $30 \mathrm{~g} / \mathrm{d}$ & Urea, $0.250 .5 \mathrm{~g} / \mathrm{kg} / \mathrm{d}$ & Urea & Urea, $1560 \mathrm{~g} / \mathrm{d}$ & \\
\hline & $\begin{array}{l}\text { Vasopressin } \\
\text { receptor } \\
\text { antagonist }\end{array}$ & $\begin{array}{l}\text { Vasopressin } \\
\text { receptor antagoni }\end{array}$ & & & $\begin{array}{l}\text { Tolvaptan } \\
1560 \mathrm{mg} / \mathrm{d}\end{array}$ & $\begin{array}{l}\text { No vasopressin } \\
\text { receptor antagonists }\end{array}$ & & & \\
\hline \multirow[t]{5}{*}{ Hypervolemia } & & $\begin{array}{l}\text { Treat underlying } \\
\text { condition }\end{array}$ & & & & & & & \\
\hline & $\begin{array}{l}\text { Fluid restriction, } \\
\text { dose dependent } \\
\text { on serum and } \\
\text { urinary electrolytes }\end{array}$ & Fluid restriction & Fluid restriction & $\begin{array}{l}\text { Fluid restriction } \\
<1,000 \mathrm{~mL} / \mathrm{d}\end{array}$ & & Fluid restriction & & $\begin{array}{l}\text { Fluid restriction, } \\
<\text { insensible losses + } \\
\text { urine output }\end{array}$ & Fluid restriction \\
\hline & Loop diuretics & Salt restriction & Salt restriction & No $\mathrm{NaCl}>0.9 \%$ & & & & Salt restriction & \\
\hline & & Demeclocycline & & $\begin{array}{l}\text { Stop } \\
\text { diuretics }\end{array}$ & & No demeclocycline & & $\begin{array}{l}\text { Possibly vasopressin } \\
\text { receptor antagonist }\end{array}$ & \\
\hline & & $\begin{array}{l}\text { Vasopressin } \\
\text { receptor } \\
\text { antagonist }\end{array}$ & & & & $\begin{array}{l}\text { No vasopressin } \\
\text { receptor antagonist }\end{array}$ & & & \\
\hline
\end{tabular}

NIV, Nederlandse Internisten Vereniging [16]; NHS, National Health Service [17]; GAIN, Guidelines and Audit Implementation Network [22]; AEEH, La Asociacin Espaola para el Estudio del Hgado [ 23]; EHN, European Hyponatremia Network [25]; ERBP, European Renal Best Practice; ESE, European Society of Endocrinology; ESICM, European Society of Intensive Care Medicine [20]; UF, University of Florida [18]; HEP, Hyponatremia Expert Panel [19]; RCH Melbourne, the Royal Children s Hospital Melbourne [21]; EAH-ICD, International Exercise-Associated Hyponatremia Consensus Development Conference [24]. 
Table 4 Summary of recommendations for targets and limits for speed of correction of hyponatremia by included guidance documents

\begin{tabular}{|c|c|c|c|c|c|c|c|c|c|c|}
\hline \multirow{3}{*}{$\begin{array}{l}\text { Criteria/ } \\
\text { categories }\end{array}$} & \multicolumn{10}{|c|}{ Guideline Organization/Societies } \\
\hline & NIV & NHS & GAIN & AEEH & EHN & ERBP/ESE/ESICM & UF & HEP & $\mathrm{RCHM}$ & $\begin{array}{l}\text { EAH- } \\
\text { ICD }\end{array}$ \\
\hline & [16] & [17] & [22] & [23] & [25] & [20] & [18] & [19] & [21] & [24] \\
\hline \multicolumn{11}{|l|}{$\begin{array}{l}\text { Targets [Na] } \\
\text { increase }\end{array}$} \\
\hline Symptoms & $\begin{array}{l}\text { Independent } \\
\text { of symptoms }\end{array}$ & If symptoms & If symptoms & & If symptoms & If symptoms & & If symptoms & $\begin{array}{l}\text { Until seizures resolve } \\
\text { or }[\mathrm{Na}]>125 \mathrm{mmol} / \mathrm{L}\end{array}$ & \\
\hline $\begin{array}{l}\text { Acute onset } \\
(<48 \mathrm{~h})\end{array}$ & $\begin{array}{l}12 \mathrm{mmol} / \mathrm{L} / \mathrm{h} \\
\text { initially }\end{array}$ & $\begin{array}{l}\text { Until }[\mathrm{Na}] \\
>120 \mathrm{mmol} / \mathrm{L} \\
\text { independent } \\
\text { of onset }\end{array}$ & $\begin{array}{l}12 \mathrm{mmol} / \mathrm{L} / \mathrm{h} \\
\text { first } 23 \mathrm{~h}\end{array}$ & & $16 \mathrm{mmol} / \mathrm{L}$ first $2 \mathrm{~h}$ & $5 \mathrm{mmol} / \mathrm{L}$ first $\mathrm{h}$ & & $\begin{array}{l}46 \mathrm{mmol} / \mathrm{L} \\
\text { urgently }\end{array}$ & Independent of onset & \\
\hline $\begin{array}{l}\text { Chronic onset } \\
\text { (>48 h) }\end{array}$ & & & $\begin{array}{l}0.51 \mathrm{mmol} / \\
\mathrm{L} / \mathrm{h} \text { first } 23 \mathrm{~h}\end{array}$ & & $16 \mathrm{mmol} / \mathrm{L}$ first $2 \mathrm{~h}$ & $5 \mathrm{mmol} / \mathrm{L}$ first $\mathrm{h}$ & & $\begin{array}{l}\text { If seizures or coma } \\
46 \mathrm{mmol} / \mathrm{L} \text { urgently, } \\
\text { otherwise } 46 \mathrm{mmol} / \mathrm{L} \\
\text { per } 24 \mathrm{~h}\end{array}$ & & \\
\hline \multicolumn{11}{|l|}{$\begin{array}{l}\text { Limits [Na] } \\
\text { increase }\end{array}$} \\
\hline Symptoms & $\begin{array}{l}\text { Independent } \\
\text { of symptoms }\end{array}$ & If no symptoms & $\begin{array}{l}\text { Independent } \\
\text { of symptoms }\end{array}$ & & $\begin{array}{l}\text { Independent of } \\
\text { symptoms }\end{array}$ & $\begin{array}{l}\text { Independent } \\
\text { of symptoms }\end{array}$ & $\begin{array}{l}\text { Independent } \\
\text { of symptoms }\end{array}$ & If no symptoms & Symptom dependent & \\
\hline $\begin{array}{l}\text { Acute onset } \\
(<48 \mathrm{~h})\end{array}$ & $\begin{array}{l}\text { If no risk of ODS } \\
\leq 10 \mathrm{mmol} / \mathrm{L} \text { per } \\
24 \mathrm{~h} \leq 18 \mathrm{mmol} / \mathrm{L} \\
\text { per } 48 \mathrm{~h} \text { If risk of } \\
\text { ODS }<8 \mathrm{mmol} / \mathrm{L} \\
\text { per } 24 \mathrm{~h}\end{array}$ & $\begin{array}{l}\leq 8 \quad 12 \mathrm{mmol} / \mathrm{L} \text { per } \\
24 \mathrm{~h} \leq 18 \mathrm{mmol} / \mathrm{L} \text { per } \\
48 \mathrm{~h}\end{array}$ & $\begin{array}{l}<12 \mathrm{mmol} / \mathrm{L} \\
\text { per } 24 \mathrm{~h}\end{array}$ & & $\begin{array}{l}\text { If no risk of ODS } \\
\leq 10 \mathrm{mmol} / \mathrm{L} \text { per } 24 \mathrm{~h} \\
\leq 18 \mathrm{mmol} / \mathrm{L} \text { per } 48 \mathrm{~h} \\
\text { If risk of ODS }<8 \mathrm{mmol} / \mathrm{L} \\
\text { per } 24 \mathrm{~h}\end{array}$ & $\begin{array}{l}\leq 10 \mathrm{mmol} / \mathrm{L} \text { first } \\
24 \mathrm{~h} \leq 8 \mathrm{mmol} / \mathrm{L} \\
\text { every } 24 \mathrm{~h} \text { thereafter }\end{array}$ & $\begin{array}{l}\leq 10 \mathrm{mmol} / \mathrm{L} \\
\text { per } 24 \mathrm{~h}\end{array}$ & No limits & $\begin{array}{l}\leq 8 \mathrm{mmol} / \mathrm{L} \text { per } 24 \mathrm{~h} \\
\text { after seizures resolve, } \\
\text { Independent of onset }\end{array}$ & \\
\hline $\begin{array}{l}\text { Chronic onset } \\
\text { (>48 h) }\end{array}$ & $\begin{array}{l}<8 \mathrm{mmol} / \mathrm{L} \\
\text { per } 24 \mathrm{~h}\end{array}$ & $\begin{array}{l}\leq 812 \mathrm{mmol} / \mathrm{L} \\
\text { per } 24 \mathrm{~h} \leq 18 \mathrm{mmol} / \mathrm{L} \\
\text { per } 48 \mathrm{~h}\end{array}$ & $\begin{array}{l}<12 \mathrm{mmol} / \mathrm{L} \\
\text { per } 24 \mathrm{~h}\end{array}$ & & $\begin{array}{l}<812 \mathrm{mmol} / \mathrm{L} \\
\text { per } 24 \mathrm{~h}<18 \mathrm{mmol} / \mathrm{L} \\
\text { per } 48 \mathrm{~h}\end{array}$ & $\begin{array}{l}\leq 10 \mathrm{mmol} / \mathrm{L} \text { first } \\
24 \mathrm{~h} \leq 8 \mathrm{mmol} / \mathrm{L} \\
\text { every } 24 \mathrm{~h} \text { thereafter }\end{array}$ & $\begin{array}{l}\leq 10 \mathrm{mmol} / \mathrm{L} \\
\text { per } 24 \mathrm{~h}\end{array}$ & $\begin{array}{l}<812 \mathrm{mmol} / \mathrm{L} \\
\text { per } 24 \mathrm{~h}<18 \mathrm{mmol} / \mathrm{L} \\
\text { per } 48 \mathrm{~h}\end{array}$ & & \\
\hline
\end{tabular}

[Na] Serum sodium concentration.

NIV, Nederlandse Internisten Vereniging [16]; NHS, National Health Service [17]; GAIN, Guidelines and Audit Implementation Network [22]; AEEH, La Asociacin Espaola para el Estudio del Hgado [ 23]; EHN, European Hyponatremia Network [25]; ERBP, European Renal Best Practice; ESE, European Society of Endocrinology; ESICM, European Society of Intensive Care Medicine [20]; UF, University of Florida [18]; HEP, Hyponatremia Expert Panel [19]; RCH Melbourne, the Royal Children s Hospital Melbourne [21]; EAH-ICD, International Exercise-Associated Hyponatremia Consensus Development Conference [24]. 
graded recommendations were based on very low and low level of evidence, while none were based on a high level of evidence. The lack of high quality evidence may have increased the part opinion had to play in framing the recommendations. In addition, the evidence that was available may have been interpreted differently dependent on the importance for decision making given to certain outcomes (e.g., serum sodium concentration). Finally, differences in personal experience due to differing availability of medications may partly explain possible differences in perception of uncertainties around drug safety.

However, it is also possible that discrepancies between guidance documents may in part be explained by differences in underlying methods of development. Quality, as assessed by AGREE II, was suboptimal at best, with only two documents obtaining a score $>50 \%$ for each of the six quality domains $[16,20]$. The findings suggest that several aspects related to methodological rigor of development, stakeholder involvement, applicability, and editorial independence could be improved, possibly improving consistency in provided guidance. This is in line with the findings of a recent overview of 42 appraisal studies including a total of 626 clinical practice guidelines across several clinical disciplines [26]. For guidelines to be trustworthy, they must be i) founded on high quality systematic reviews, ii) include the relevant stakeholders, and iii) be applicable in clinical practice [9].

Only half of the guidance groups stated they had conducted a systematic review of the evidence. Save one, the reviews would not have met the Institute of Medicines criteria for reporting high-quality systematic reviews [20,27], because key methods for finding and assessing individual studies as well as synthesizing the body of evidence were not described. Conducting high-quality systematic reviews requires specific methodological expertise and support which may not be available to most groups [27]. One solution might be to harmonize effort across organizations, thus focusing resources, allowing higher quality reviews and reducing duplication and possibly inconsistency between guidelines.

Six groups included healthcare professionals from different specialties [16,18,20,22,24,25]. Multidisciplinary contribution serves to broaden the approach to health-care problems, increase the completeness of evidence-finding strategies, and help to identify hurdles to implementation. When reflecting on approaches to hyponatremia, bringing together several disciplines mirrors the clinical reality of multiple specialty areas dealing with the same problem but looking at it from a different angle. Only one of the development groups reported considering patients views and experiences, but even then did so to a limited extent [20]. Decisions on clinical care should factor in patient values and preferences. Interventions for chronic hyponatremia, such as fluid restriction, may affect quality of life and patient preference should influence the ultimate recommendations.

Low scores for applicability mostly reflect the absence of describing barriers to guideline implementation and failure to provide tools for putting the recommendations into practice. In part, guidelines are designed to deal with the challenges of increasing knowledge and time-pressure. They are designed to help make decisions at the point of care. However, being often lengthy publications without layered presentation of information, it is likely that the majority of the guidance documents may not reach their target audience or stimulate implementation. Four guidance documents provided algorithms for diagnosis or treatment $[16,18,20,25]$; although these are likely to increase the utility of a guideline, it is unclear to what extent they truly improve implementation of the recommendations. How to best communicate evidence-based recommendations to the relevant stakeholders is a recent but active area of research lead by the DECIDE consortium [28]. With results of their research expected, guideline developers will have additional targets for improving the applicability in the future.

To our knowledge, this is the first attempt to systematically synthesize and appraise clinical guidelines on the diagnosis and treatment of hyponatremia In accordance with the Prisma statement, we conducted a comprehensive literature search and searched an additional 337 websites of specialist societies and guideline organizations [29] (Additional file 6). We used AGREE II, a validated and reliable instrument, and an adequate number of reviewers to individually appraise the guidance documents [30]. On top of the individual appraisals, we included an attempt to resolve major discrepancies and increase consistency by introducing an audiotaped group consensus meeting. During this meeting, reviewers could explain and motivate their scores and adapt them if they wanted to. This mostly resulted only in modest downgrading of domain scores by $1 \%$ to $10 \%$. Most of the changes happened because reviewers felt they had scored inconsistently for a same rationale, or because they missed information during the initial appraisal that was in fact available in the document. Although the scores did not change substantially, the group felt the discussion further highlighted the qualitative differences between the guidance documents. In addition, even the reviewers with large deviations from the mean in their initial scores felt they agreed with the conclusion. It means that final average scores were truly a product of consensus rather than a mathematical calculation, as proposed in the original AGREE protocol. We believe that a consensus meeting is valuable in any guideline appraisal process, and particularly useful if reviewer groups have the intention to select a guideline for local use. 
This study has its limitations. We based our assessment on what guideline organizations actually reported. Reporting by guideline developers may not wholly reflect what occurred in practice with respect to the AGREE criteria, and we did not seek additional clarification. However, contacting guideline developers is not standard practice when using AGREE as the instrument specifically aims to provide a framework for assessing the quality of reporting of recommendations. We aimed to summarize the existing recommendations on diagnosis and treatment of hyponatremia as formulated by other guideline development groups and to evaluate the quality of the guideline development process. We did not aim to summarize or critically appraise the evidence base itself. Consequently, it is difficult to assess to what extent differences between guidance documents stem from differences in development procedures rather than important limitations in the evidence base that underpin individual recommendations. Secondly, the purpose of using the AGREE instrument was not to accuse guideline development groups of being biased, but rather to highlight both strengths and weaknesses of existing guidance to suggest on how we could make improvements in the future.

Calculation of summary scores for each domain across reviewers required summing up all the scores of the individual items in a domain for each reviewer and then standardizing this total as a percentage of the maximum possible score for that domain. In doing so, the originally semi-qualitative Likert scale was converted to a quantitative score. This may have introduced numeric differences between the guidance documents that were beyond the discriminatory ability of the tool and possibly negligible in practice. Finally, we acknowledge that four of the authors of this paper also authored one of the guidelines included in this review. Although we aimed to judge all guidance documents fairly against the criteria outlined by the AGREE instrument, we cannot rule out that a subconscious intellectual competing interest unduly influenced the scoring.

\section{Conclusions}

Current guidelines on the assessment and treatment of hyponatremia often fail to meet methodological criteria for development and reporting as described by AGREE II. Despite many similarities, recommendations are sometimes inconsistent, but to what extent this is attributable to the underlying development process remains unclear.

\section{Additional files}

Additional file 1: Table S1. Search strategies.

Additional file 2: Table S2. Data extraction template.
Additional file 3: Table S3. Structure and content of the AGREE instrument.

Additional file 4: Table S4. Table of excluded studies.

Additional file 5: Table S5. Mean scores across reviewers for the individual AGREE II domain items.

Additional file 6: PRISMA checklist.

\section{Abbreviation}

AGREE II: Appraisal of guidelines for research and evaluation II.

\section{Competing interests}

Evi Nagler is a member of the Methods Support Team of European Renal Best Practice (ERBP). She is also one of the authors of the Clinical Practice Guideline on the diagnosis and treatment of hyponatremia, developed in a joint venture with the European Society of Endocrinology and the European Society of Intensive Care Medicine and one of the guidelines included in the current review. Jill Vanmassenhove has no relevant disclosures. Sabine van der Veer is a member of the Methods Support Team of European Renal Best Practice (ERBP). She is also one of the authors of the Clinical Practice Guideline on the diagnosis and treatment of hyponatremia, developed in a joint venture with the European Society of Endocrinology and the European Society of Intensive Care Medicine and one of the guidelines included in the current review. Ionut Nistor is a member of the Methods Support Team of ERBP. Wim Van Biesen is the Chair of ERBP, he is also one of the authors of the Clinical Practice Guideline on the diagnosis and treatment of hyponatremia, developed in a joint venture with the European Society of Endocrinology and the European Society of Intensive Care Medicine and one of the guidelines included in the current review. Angela Webster has no relevant disclosures. Raymond Vanholder is member of ERBP, he is also one of the authors of the Clinical Practice Guideline on the diagnosis and treatment of hyponatremia, developed in a joint venture with the European Society of Endocrinology and the European Society of Intensive Care Medicine and one of the guidelines included in the current review.

\section{Authors contributions}

EN designed and conducted the systematic review, conducted the systematic search, selected and critically appraised the studies, collected the data, and wrote and revised the manuscript. JV selected and critically appraised the studies, collected the data, and revised the manuscript. SVDV critically appraised the studies. IN conducted the systematic search and critically appraised the studies. WVB designed the systematic review, critically appraised the studies, and wrote and revised the manuscript. AW designed the systematic review and wrote and revised the manuscript. RV designed the systematic review and wrote and revised the manuscript. All authors read and approved the final manuscript.

\section{Acknowledgements}

Evi Nagler, Sabine van der Veer, and lonut Nistor are fellows of the Methods Support Team of European Renal Best Practice (ERBP), supported by a grant of the European Renal Association- European Dialysis Transplantation Association (ERA-EDTA).

\section{Author details}

${ }^{1}$ European Renal Best Practice (ERBP), guidance body of the European Renal Association European Dialysis and Transplant Association (ERA-EDTA), De Pintelaan 185, Ghent 9000, Belgium. ${ }^{2}$ Renal Division, Department of Internal Medicine, Ghent University Hospital, De Pintelaan 185, Ghent 9000, Belgium. ${ }^{3}$ Centre for Kidney Research, The Children s Hospital at Westmead, Locked Bag 4001, Westmead 2145, NSW, Australia. ${ }^{4}$ Department of Medical Informatics, Academic Medical Center, Postbus 22660, Amsterdam 1100DD, the Netherlands. ${ }^{5}$ Nephrology Department, Gr. T. Popa University of Medicine and Pharmacy, Strada Universittii 16, lasi 700115, Romania. ${ }^{6}$ Sydney School of Public Health, Edward Ford Building (A27), The University of Sydney, NSW 2006, Australia. ${ }^{7}$ Centre for Transplant and Renal Research, The University of Sydney at Westmead Hospital, Westmead 2145, NSW, Australia.

Received: 20 April 2014 Accepted: 7 November 2014

Published online: 11 December 2014 


\section{References}

1. Ellison DH, Berl T: Clinical practice. The syndrome of inappropriate antidiuresis. N Engl J Med 2007, 356:2064 2072.

2. Upadhyay A, Jaber BL, Madias NE: Epidemiology of hyponatremia. Semin Nephrol 2009, 29:227 238.

3. Liamis G, Rodenburg EM, Hofman A, Zietse R, Stricker BH, Hoorn EJ: Electrolyte disorders in community subjects: prevalence and risk factors. Am J Med 2013, 126:256 263.

4. Wald R, Jaber BL, Price LL, Upadhyay A, Madias NE: Impact of hospitalassociated hyponatremia on selected outcomes. Arch Intern Med 2010, 170:294 302.

5. Hoorn EJ, Lindemans J, Zietse R: Development of severe hyponatremia in hospitalized patients: treatment-related risk factors and inadequate management. Nephrol Dial Transplant 2006, 21:70 76.

6. Huda MSB, Boyd A, Skagen K, Wile D, van Heyningen C, Watson I, Wong S, Gill G: Investigation and management of severe hyponatremia in a hospital setting. Postgrad Med 2006, 82:216 219

7. Fenske W, Maier SKG, Blechschmidt A, Allolio B, Stork S: Utility and limitations of the traditional diagnostic approach to hyponatremia: a diagnostic study. Am J Med 2010, 123:652 657.

8. Sterns RH, Nigwekar SU, Hix JK: The treatment of hyponatremia. Semin Nephrol 2009, 29:282 299.

9. Committee on Standards for Developing Trustworthy Clinical Practice Guidelines, Board on Health Care Services, Institute of Medicine: In Clinical Practice Guidelines We Can Trust. Edited by Graham R, Mancher M, Wolman DM, Greenfield S, Steinberg E. US: The National Academies Press; 2011.

10. Glujovsky D, Bardach A, Garca Mart S, Comand D, Ciapponi A: EROS: a new software for early stage of systematic reviews. Value Health 2011, 14:A564.

11. Brouwers M, Kho ME, Browman GP, Burgers JS, Cluzeau F, Feder G, Fervers B, Graham ID, Grimshaw J, Hanna SE, Littlejohns P, Makarski J, Zitzelsberger L, AGREE Next Steps Consortium: AGREE II: Advancing guideline development, reporting and evaluation in healthcare. Can Med Ass J 2010, 182:E839 E842.

12. Collaboration AGREE: Development and validation of an international appraisal instrument for assessing the quality of clinical practice guidelines: the AGREE project. Qual Saf Health Care 2003, 12:18 23

13. Tong A, Chapman JR, Wong G, de Bruijn J, Craig JC: Screening and follow-up of living kidney donors: a systematic review of clinical practice guidelines. Transplantation 2011, 92:962 972.

14. Lopez-Olivo MA, Kallen MA, Ortiz Z, Skidmore B, Suarez-Almazor ME: Quality appraisal of clinical practice guidelines and consensus statements on the use of biologic agents in rheumatoid arthritis: a systematic review. Arthritis Rheum 2008, 59:1625 1638.

15. AGREE: Advancing the science of practice guidelines. [http://www.agreetrust.org/resource-centre/agree-ii-training-tools/]

16. Geers ABM, Tuut MK, Hoorntje SJ, van Saase JLCM, Zietse R: Electrolytstoornissen. NIV: Hoorn EJ; 2012. [http://www.internisten.nl]. Accessed 01 January 2013.

17. Clinical Knowledge Summaries: Prodigy Topic on Hyponatremia. 2011, [http://www.cks.nhs.uk/hyponatremia]. Accessed 02 January 2013.

18. Rahman M, Friedman WA: Hyponatremia in neurosurgical patients: clinical guidelines development. Neurosurgery 2009, 65:925 935.

19. Verbalis JG, Goldsmith SR, Greenberg A, Korzelius C, Schrier RW, Sterns RH, Thompson CJ: Diagnosis, evaluation, and treatment of hyponatremia: Expert panel recommendations. Am J Med 2013, 126:S1 S42.

20. Spasovski G, Vanholder R, Allolio B, Annane D, Ball S, Bichet D, Decaux G, Fenske W, Hoorn E, Ichai C, Joannidis M, Soupart A, Zietse R, Haller M, van der Veer S, Van Biesen W, Nagler E, Hyponatraemia Guideline Development Group: Clinical practice guideline on diagnosis and treatment of hyponatremia. Nephrol Dial Transplant 2014, 29:i1 i39.

21. Royal Children's Hospital Melbourne Australia: Clinical Practice Guideline on Hyponatremia. [http://www.rch.org.au/clinicalguide/index.cfm]. Accessed 02 January 2013.

22. Hyponatremia in Adults (On or after 16th Birthday). [http://www.gain-ni. org]. Accessed 03 January 2013.

23. Gines P, Cabrera J, Guevara M, Morillas R, Ruiz del Arbol L, Solae R, Soriano $\mathrm{G}$ : Consensus document on the treatment of ascites, dilutional hyponatremia and hepatorenal syndrome in liver cirrhosis. Gastroenterol Hepatol 2004, 27:535 544.

24. Hew-Butler T, Ayus JC, Kipps C, Maughan RJ, Mettler S, Meeuwisse WH, Page AJ, Reid SA, Rehrer NJ, Roberts WO, Rogers IR, Rosner MH, Siegel AJ,
Speedy DB, Stuempfle KJ, Verbalis JG, Weschler LB, Wharam P: Statement of the Second International Exercise-Associated Hyponatremia Consensus Development Conference, New Zealand, 2007. Clin J Sport Med 2008, 18:111 121 .

25. Runkle I, Villabona C, Navarro A, Pose A, Formiga F, Tejedor A, Poch E, European Hyponatremia N: The treatment of hyponatremia secondary to the syndrome of inappropriate antidiuretic hormone secretion. Medicina Clnica 2013, 141:e501 e510.

26. Alonso-Coello P, Irfan A, Sol I, Gich I, Delgado-Noguera M, Rigau D, Tort S, Bonfill X, Burgers J, Schunemann H: The quality of clinical practice guidelines over the last two decades: a systematic review of guideline appraisal studies. Qual Saf Health Care 2010, 19:e58.

27. Committee on Standards for Systematic Reviews of Comparative Effectiveness Research, Board on Health Care Services, Institute of Medicine: In Finding What Works in Health Care: Standards for Systematic Reviews. Edited by Eden J, Levit L, Berg A, Morton S. US: The National Academies Press; 2011.

28. Treweek S, Oxman A, Alderson P, Bossuyt P, Brandt L, Brozek J, Davoli M, Flottorp S, Harbour R, Hill S, Liberati A, Liira H, Schnemann HJ, Rosenbaum S, Thornton J, Vandvik PO, Alonso-Coello P, DECIDE Consortium: Developing and evaluating communication strategies to support informed decisions and practice based on evidence (DECIDE): protocol and preliminary results. Implementation Science 2013, 8:6.

29. Moher D, Liberati A, Tetzlaff J, Altman DG: Preferred Reporting Items for Systematic Reviews and Meta-Analyses: The PRISMA Statement. PLoS Med 2009, 6:e1000097. doi:10.1371/journal.pmed1000097.

30. Irani S, Rashidian A, Yousefi-Nooraie R, Soltani A: Evaluating clinical practice guidelines developed for the management of thyroid nodules and thyroid cancers and assessing the reliability and validity of the AGREE instrument. J Eval Clin Pract 2011, 17:729 736.

doi:10.1186/s12916-014-0231-1

Cite this article as: Nagler et al.: Diagnosis and treatment of hyponatremia: a systematic review of clinical practice guidelines and consensus statements. BMC Medicine 2014 12:231.

\section{Submit your next manuscript to BioMed Central and take full advantage of:}

$\otimes$ Convenient online submission

$\otimes$ Thorough peer review

$\otimes$ No space constraints or color $\nabla$ gure charges

$\otimes I m m e d i a t e$ publication on acceptance

\Inclusion in PubMed, CAS, Scopus and Google Scholar

$\otimes$ Research which is freely available for redistribution

Submit your manuscript at www.biomedcentral.com/submit
C Biomed Central 